\title{
FITOSSOCIOLOGIA DA ARAUCARIA ANGUSTIFOLIA CBERT.J KUNTZE EM ÁREA DE RELEVANTE INTERESSE ECOLÓGICO, PATO BRANCO, PARANÁ, BRASIL
}

\author{
PHYTOSOCIOLOGY OF ARAUCARIA ANGUSTIFOLIA CBERT.J KUNTZE IN AREA OF RELEVANT ECOLOGICAL \\ INTEREST, PATO BRANCO, PARANÁ, BRAZZL
}

Emanueli Pereira da Silva'

Luciana Pelizzarro²

\section{Resumo}

A espécie arbórea Araucaria angustifolia é uma Gimnosperma que apresenta caráter dominante nas formações florestais onde é encontrada. Embora possua importante papel ecológico no seu ecossistema e no estabelecimento de novos reflorestamentos, encontra-se na Lista Oficial de Espécies Ameaçadas de Extinção. Essa condição mostra a importância das unidades de conservação para protegê-la. Esta pesquisa objetivou analisar a fitossociologia da espécie arbórea Araucaria angustifolia de um fragmento de Floresta Ombrófila Mista da Área de Relevante Interesse Ecológico (Ariê) do Buriti, localizada na cidade de Pato Branco, Paraná. Utilizou-se a metodologia de múltiplas parcelas para determinar a área amostral, a qual foi representada por dezesseis parcelas quadradas $(50 \times 50 \mathrm{~m})$, onde foram coletados dados para determinação de frequência, dominância e densidade da espécie $A$. angustifolia. Resultados mostraram que a espécie alvo apresentou densidade relativa de 6,54\%; densidade absoluta de 1,0 ind/ha; frequência absoluta de $81,25 \%$ e dominância absoluta de $0,38 \mathrm{~m}^{2} /$ ha.

Palavras-chave: dendrologia, floresta ombrófila mista, mata de araucária, unidade de conservação.

\begin{abstract}
The arboreal species Araucaria angustifolia is a gymnosperm that presents dominant character in the forest formations where it is found. Although it has an important ecological role in its ecosystem and the establishment of new afforestation, it is in the Official List of Endangered Species. This condition shows the importance of conservation units to protect it. This research aimed to analyze the phytosociology of the arboreal species Araucaria angustifolia from a Mixed Ombrophilous Forest fragment of the Area of Relevant Ecological Interest (Arie) of Buriti, located in the city of Pato Branco, Paraná, Brazil. The multiple plot method was used to determine the sample area, which was represented by sixteen square plots $(50 \times 50 \mathrm{~m}$ ), where data were collected for frequency, dominance and density of $A$. angustifolia. The target species had a relative density of $6.54 \%$; absolute density of 1.0 ind ha; absolute frequency of $81.25 \%$ and absolute dominance of $0.38 \mathrm{~m}^{2}$ ha.
\end{abstract}

1 UTFPR. E-mail: eps.emanueli@gmail.com

2 E-mail: manunuti.95@gmail.com 
Keywords: dendrology, mixed ombrophylous forest, araucaria forest, conservation unit.

\section{INTRODUÇÃO}

A fitossociologia é a ciência que busca descrever e compreender a associação existente entre as espécies vegetais dentro de uma comunidade ecológica (Chaves et al. 2013). É uma ferramenta de grande utilidade na determinação do papel e da importância de espécies em seus respectivos ecossistemas, possibilitando definir graus de hierarquização ou dominância, além de possibilitar a obtenção de dados quantitativos que são parâmetros importantes na realização de técnicas como manejo e conservação.

A espécie arbórea Araucaria angustifolia (Bert) O. Kuntze é uma Gimnosperma que pode atingir alturas superiores a 20 metros e viver até 300 anos. Apresenta caráter dominante em vegetações onde é encontrada e, considerando sua importância ecológica, cria condições que podem facilitar o desenvolvimento de outras espécies vegetais, como as da família Myrtaceae, a erva-mate (Ilex paraguariênsis A. St.Hil) e o xaxim (Dicksonia sellowiana (Presl) Hook. ), por meio de sombreamento (Nascimento et al. 2001). Da mesma forma, pode ser utilizada em práticas de regeneração de florestas representando grande parte dos indivíduos do estrato superior. Sua semente, o pinhão, serve como alimento para mamíferos e aves durante o inverno. Embora isso, encontra-se na Lista Oficial de Espécies da Flora Brasileira Ameaçadas de Extinção (Brasil 2014).

Devido a essa possibilidade de extinção das araucárias, algumas Unidades de Conservação (UC) podem protegê-la. As UCs classificam-se em dois grupos: Unidades de Proteção Integral e Unidades de Uso Sustentável. Inclusas no grupo de Unidades de Uso Sustentável estão as Áreas de Relevante Interesse Ecológico (Ariês), que têm como objetivo conservar uma biota diferente de um contexto botânico regional (Brasil 200o).

A Ariê do Buriti está situada na área rural do município de Pato Branco, Paraná, com área total de 81,5 ha. Foi inicialmente criada com o objetivo de preservar a espécie Mauritia flexuosa L., uma palmeira ameaçada de extinção, conhecida como palmeira-buriti, pois havia registro da sua ocorrência na Ariê. No entanto, estudos realizados nessa unidade demonstraram que a palmácea pertence a outra espécie, identificada como Trithrinax brasiliensis Mart. var. acanthocoma (Drude) Mattos (Carrijo 2013). Assim, a Ariê do Buriti abriga e conserva essa palmácea, cujos indivíduos se misturam à vegetação de um fragmento florestal, originalmente de Floresta Ombrófila Mista (FOM), pertencente ao Bioma Mata Atlântica (Carrijo 2013, Lustosa 2006). A vegetação florestal da Ariê do Buriti é secundária, pois parte dela foi revegetada com a espécie $A$. angustifolia, nos anos de 1991. Sendo assim, algumas 
porções da UC contêm maior quantidade desta espécie em relação a outras, que são espécies típicas da FOM, em diferentes estágios sucessionais, dependendo da porção.

O presente trabalho teve como objetivo a realização de um estudo fitossociológico da $A$. angustifolia na Ariê do Buriti, de forma a obter dados que podem auxiliar na compreensão da estrutura e dinâmica da mesma, bem como em futuros projetos de reposição da vegetação que venham a ser necessários na unidade. Tendo em vista as regiões da Ariê que receberam plantio de A. angustifolia, os dados possibilitarão também comparativos futuros sobre o desenvolvimento da vegetação nas diferentes regiões: naturais e reflorestadas .

\section{MATERIAL E MÉTODOS}

A coleta de dados ocorreu na mata da Área de Relevante Interesse Ecológico (Ariê) do Buriti (Figura 1), situada na área rural do município de Pato Branco, na estrada Pioneiro Irineu Bertani, s/n', Localidade Linha Independência (26 $11^{\prime} 20^{\prime} S$, $\left.52^{\circ} 45^{\prime} 58^{\prime \prime} \mathrm{W}\right)$ no Sudoeste do Estado do Paraná.

Possui área total de 81,5 ha. A vegetação é constituída por espécies da FOM e parte dela foi reflorestada com A. angustifolia. A Ariê foi instituída como Unidade de Conservação em 1990 e tem como órgão gestor o Instituto Ambiental do Paraná (IAP).

A coleta de dados ocorreu entre o mês de julho de 2016 e setembro de 2017 .

Para a coleta dos dados foi utilizada a metodologia de múltiplas parcelas quadradas, devido à facilidade de instalação e ao formato da área de estudo (Sanquetta et al. 2009). Foram distribuídas dezesseis parcelas de 50x50 m (o,25 ha) cada uma delas, sendo a área total amostrada de 4 ha. As parcelas foram distribuídas em intervalos de aproximadamente $150 \mathrm{~m}$ entre elas e cada uma delas foi determinada por uma letra (Figura 1). Todos os indivíduos arbóreos com CAP $\geq 15 \mathrm{~cm}$ (Soares et al. 2006) e altura superior a 2,0 m, nelas contidos, receberam uma placa metálica com número de identificação, a fim de que não fossem considerados mais de uma vez e para que possam ser encontrados futuramente, caso haja necessidade.

Representantes da espécie $A$. angustifolia foram contabilizados em um grupo (A) e as demais espécies em outro grupo único (B). Todas as informações coletadas em campo foram registradas em planilhas.

Os parâmetros analisados, de acordo com Oliveira \& Amaral (2004), foram:

- Densidade relativa (DR), que calcula a percentagem do número de indivíduos de uma determinada espécie em relação ao total de espécies.

$$
\text { Dri }=\text { ni.10o/N }
$$

Em que: $\mathrm{ni}=\mathrm{n}^{\circ}$ de indivíduos da espécie $\mathrm{i} ; \mathrm{N}=\mathrm{n}^{\circ}$ total de indivíduos.

Densidade absoluta ( $\mathrm{Da})$, que representa o número médio de árvores de uma espécie por unidade de área. 
Em que: ni= número de indivíduos da espécie $\mathrm{i} ; \mathrm{A}=$ área total amostrada em $\mathrm{m}^{2}$; U=Unidade amostral.

Frequência absoluta (FA), que determina a percentagem de unidades de amostragem com ocorrência de espécies, em relação ao número total de unidades de amostragem.

$\mathrm{FAi}=\mathrm{Pi} .100 / \mathrm{P}$

(Equação 3)

Em que: $\mathrm{Pi}=\mathrm{n}^{\circ}$ de parcelas de amostragem em que a espécie ocorreu; $\mathrm{P}=\mathrm{n}^{\circ}$ total de parcelas.

Dominância absoluta (DoA), que apresenta a somatória da área basal dos indivíduos de cada espécie.

$\mathrm{DoAi}=\mathrm{ABi} . \mathrm{U} / \mathrm{A}$

(Equação 4)

Em que: $\mathrm{ABi}$ = área basal dos indivíduos da espécie; $\mathrm{U}=$ Unidade amostral; $\mathrm{A}=$ área total amostrada.

\section{RESULTADOS E DISCUSSÃO}

Foram contabilizadas 204 representantes da espécie A. angustifolia e 3118 indivíduos de outras espécies arbóreas com circunferência à altura do peito $\geq 15 \mathrm{~cm}$ e altura superior a $2 \mathrm{~m}$, havendo diferença de distribuição em cada parcela

As parcelas com maior número de indivíduos da espécie A. angustiolia foram as estabelecidas na área florestada com a espécie (F, G e H). Em tres parcelas (B, D e E) a espécie não foi encontrada, e apresentou de um a oito indivíduos nas demais parcelas cuja formação florestal é natural, sem plantio da araucária.

Os indivíduos de A. angustifolia que compõem as parcelas de áreas naturais, sem rereflorestamento, são mais antigos e possivelmente estão lá há dezenas de anos, tendo sido poupados do corte na época da colonização da região (Figura 1), pois a área da Ariê, assim como toda a Região do município de Pato Branco, sofreu grande ação antrópica na época e a espécie $A$. angustifolia possuía significativo interesse econômico, devido à utilização de sua madeira para a fabricação de casas ou partes de sua estrutura, produção de utensílios domésticos, instrumentos musicais e também como combustível de caldeiras, entre outros (Guerra et al. 2002, Lustosa 2006). 


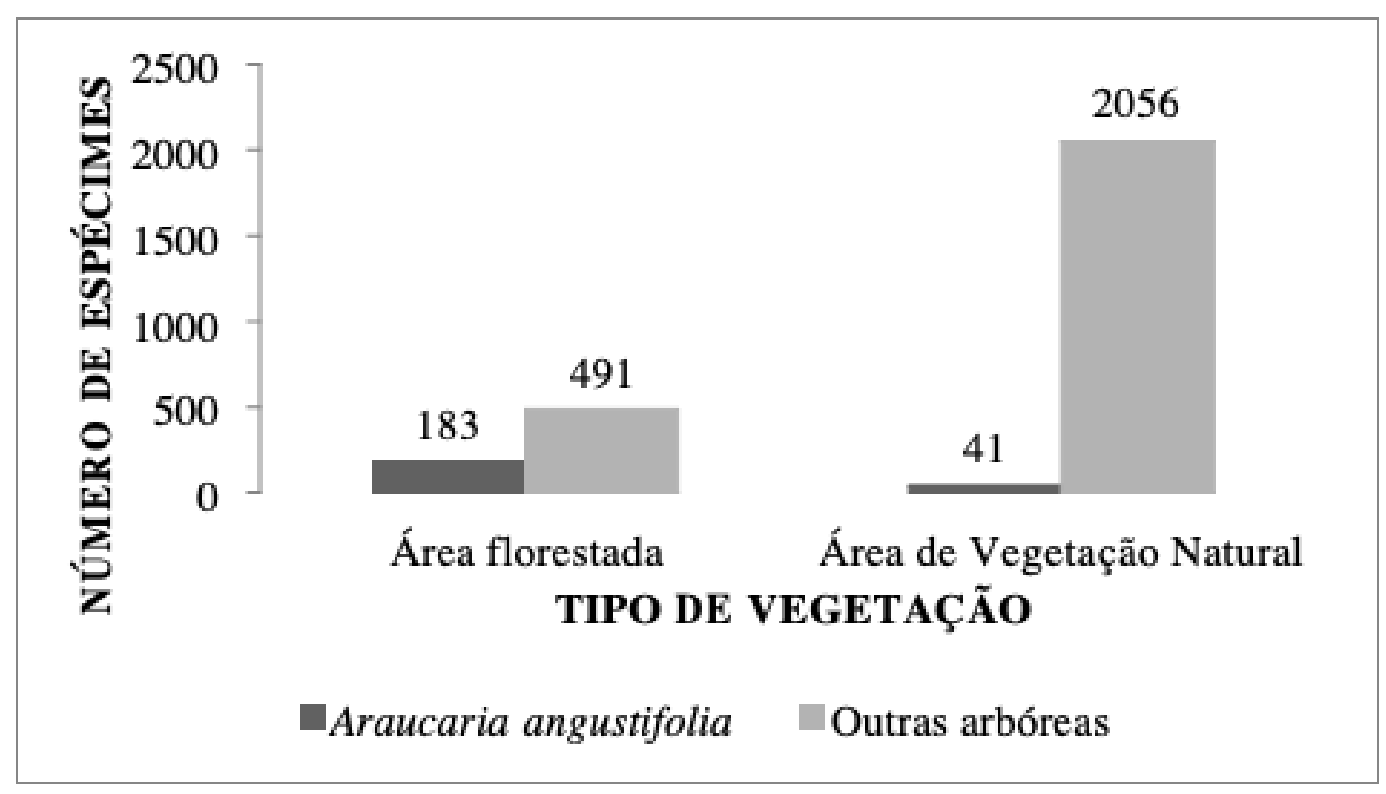

Figura 1. Proporção de indivíduos em área florestada e em área de floresta natural, na Área de Relevante Interesse Ecológico do Buriti, Pato Branco, Paraná, 2020.

Quanto aos parâmetros fitossociológicos (Tabela 2), A. angustifolia apresentou densidade relativa (DR) de 6,54\% e densidade absoluta (DA) de 1,0 ind. ha. Embora a área tenha sido florestada com $A$. angustifolia há aproximadamente duas décadas, a densidade absoluta apresentada pela espécie é considerada baixa em relação a outros estudos como o de Meyer et al. (2013) no Estado de Santa Catarina, em que a espécie apresentou 20,90 ind. ha para DA. Possivelmente esse parâmetro esteja relacionado à exploração madeireira da espécie, ocorrida desde o início do século XX na região e ao seu baixo índice de regeneração em matas antropizadas (Carrijo 2013).

A frequência absoluta (FA) foi de $81,25 \%$ e é alta quando comparada à FA da espécie em remanescente de FOM em São Francisco de Paula (RS), que foi de $8 \%$ (Silva 2015) e em Caçador (SC), que foi de 38,57\% (Negrelle \& Silva 1992). Porém, como já visto, mesmo ela estando presente em quase todas as parcelas amostradas, sua DA é baixa, ou seja, distribui-se por quase toda a área, mas com poucos ou nenhum representante em algumas porções da Ariê.

Tabela 1. Parâmetros fitossociológicos da Araucaria angustifolia na Área de Relevante Interesse Ecológico do Buriti, Pato Branco, Paraná, 2020.

\begin{tabular}{c|c|c|c|c|c}
\hline \multirow{2}{*}{ Espécie } & \multicolumn{5}{c}{ Parâmetros } \\
\cline { 2 - 6 } & $\mathrm{n}$ & FA (\%) & DA (ind. ha) & DR (\%) & DoA (m² ha) \\
\hline Araucaria angustifolia & 224 & 81,25 & 1,0 & 6,54 & 0,38 \\
\hline
\end{tabular}

Legenda: $\mathrm{ni}=$ números de indivíduos da amostragem; $\mathrm{FA}=$ frequência absoluta; $\mathrm{DA}=$ densidade absoluta; $\mathrm{DR}=$ densidade relativa; $\mathrm{DoA}$ = dominância absoluta. 
A dominância absoluta (DoA) foi de $0,38 \mathrm{~m}^{2}$ ha, demonstrando que os representantes da espécie, considerados no todo, possuem base relativamente pequena, o que se explica pelo fato de parte dos indivíduos serem resultantes do reflorestamento lá realizado. Se a DA e/ou a FA forem altas, a DoA será alta também. O resultado da DoA é baixo em relação à área de floresta primária localizada em Passos Maia (SC) com DoA de 1,6 $\mathrm{m}^{2}$ ha (Fabris 2010), mas semelhante a matas secundárias, como a de São Francisco de Paula, cuja DoA foi estimada em o,79 $\mathrm{m}^{2}$ ha (Silva 2015).

\section{CONCLUSÃO}

É possível observar que a Ariê do Buriti possui parâmetros semelhantes às demais UC's, exceto em relação à dominância. Desta forma, pode-se inferir que, assim que os indivíduos estiverem com porte maior, a dominância pode assemelharse a áreas de UC melhor conservadas. A alta frequência pode permitir que a espécie propague-se naturalmente, de forma também bem distribuída, se a Ariê oferecer condições apropriadas para tal, como a ausência de antropização negativa.

\section{LITERATURA CITADA}

Brasil. 200o. Ministério do Meio Ambiente. Lei no 9.985, de 18-VII-200o. Institui o Sistema Nacional de Unidades de Conservação da Natureza. Diário Oficial da União, Ministério do Meio Ambiente, Brasília, 19-VII-200o. Seção 1, p. o1. http:// www.planalto.gov.br/ccivil_03/leis/l9985.htm\#: :text=L9985\&text=LEI\%20No\%20 9.985\%2C\%2oDE\%2018\%2oDE\%20JULHO\%2oDE\%20200o.\&text=Regulamenta\%20 o\%2oart.,Natureza\%2oe\%2od\%C3\%A1\%2ooutras\%2oprovid\%C3\%AAncias.

Brasil. 2014. Ministério do Meio Ambiente. Portaria $n^{\circ} 443$, de $17-X I I-2014$. Lista Nacional Oficial de Espécies da Flora Ameaçadas de Extinção. Diário Oficial da União, Ministério do Meio Ambiente, Brasília, 18-XII-2014,. Seção 1, pp. 110-121. http:// cncflora.jbrj.gov.br/portal/static/pdf/portaria_mma_443_2014.pdf

Carrijo, B. R. 2013. Uma análise geográfica da Área de Relevante Interesse Ecológico (Ariê Buriti), Pato Branco - PR, a partir dos conceitos geossistema-território-paisagem. Tese de Doutorado, Universidade Federal do Paraná, Curitiba. https://acervodigital. ufpr.br/bitstream/handle/1884/31926/R\%20-\%2oT\%2o-\%2oBEATRIZ\%2o RODRIGUES\%2oCARRIJO.pdf? sequence $=1 \&$ isAllowed $=\mathrm{y}$

Chaves, A. C. G., Santos, R. M. S., Santos, J . O., Fer nandes, A. A. \& Maracaja, P. B. 2013. A importância dos levantamentos florístico e fitossociológico para conservação 
e preservação das florestas. Revista Agropecuária Científica no Semiárido 9: 42-48. http://revistas.ufcg.edu.br/acsa/index.php/ACSA/article/view/449/pdf

Guerra, M.P., Silveira, V., Reis, M. S. \& Schneider, L. 2002. Exploração, manejo e conservação da araucária (Araucaria angustifolia ). In: Simões, L. L. \& Lino, C.F. (eds.). Sustentável Mata Atlântica: a exploração de seus recursos florestais. Senac, São Paulo, pp. 85-101.

Lustosa, C. A. 2006. Análise de atividades desenvolvidas e mudanças ocorridas durante o período de 2003 a 2006 na Área de Relevante Interesse Ecológico do Buriti no município de Pato Branco-PR. Monografia de Pós-Graduação, Universidade Estadual do Oeste do Paraná, Francisco Beltrão.

Meyer, L., Gasper, A. L., Sevegnani, L., Schor n, L. A., Vibrans, A. C., Lingner, D. V., Verdi, M., Stivalsantos, A., Dreveck, S. \& Korte, A. 2013. Regeneração natural da Floresta Ombróila Mista em Santa Catarina. In: Vibrans, A. C., Sevegnani, L., Gasper, A. L., Lingner, D. V. (Ed.). Inventário florístico florestal de Santa Catarina: Floresta Ombrófila Mista. Edifurb, Blumenau, pp. 191-222.

Nascimento, A. R. T., Longui, S. J. \& Brena, D. A. 2001. Estrutura e padrões de distribuição espacial de espécies arbóreas em uma amostra de Floresta Ombrófila Mista em Nova Prata, RS. Ciência Florestal 11: 105-19. https://www.scielo.br/pdf/cflo/ v11n1/1980- 5098-cflo-11-01-105.pdf

Oliveira, A. N. \& Amaral, I. L. 2004. Florística e fitossociologia de uma floresta de vertente na Amazônia Central, Amazonas, Brasil. Acta Amazônica 34:21-24. https:// www.scielo.br/pdf/aa/v34n1/v34n1ao4.pdf

Sanquetta, C. R., Watzlawick, L.F., Dalla Côr te, A. P. \& Fer nandes, L. A. V. 2009. Inventários Florestais: Planejamento e Execução. Mult-Graf \& Editofa, Curitiba.

Soares, C. P. B., Paula, F. N. \& Souza, A. L. 2006. Dendometria e Inventário Florestal. UFV, Viçosa. 